\title{
P237: Nosocomial infections and infectious agents determined in geriatric patients
}

\author{
H Gül ${ }^{1}$, A Karakaş ${ }^{1}$, C Artuk $^{1 *}$, S Aytemiz², G Mert ${ }^{1}$, CP Eyigün ${ }^{1}$ \\ From 2nd International Conference on Prevention and Infection Control (ICPIC 2013) \\ Geneva, Switzerland. 25-28 June 2013
}

\section{Introduction}

Parallel to the increase in the elderly population, various health policies including materialistic and moral policies have been developed for this patient group worldwide, especially in developed countries.

\section{Objectives}

The aim of this study was to determine the nosocomial infections that emerge during the hospitalization of the elderly population, the risk factors for these infections and the mortality rates.

\section{Methods}

The frequencies, types, agent distributions and the emerging periods of nosocomial infections, and the risk factors for these infections in patients aged 65 and over, who had been treated and followed-up in GMMA in 2011, were retrospectively evaluated.

\section{Results}

610 nosocomial infections were observed in 400 patients in our hospital in 2011. 188 of these patients were geriatric patients and 279 nosocomial infections were determined among them. 77 of the patients were female and 111 were male. The mean age was $76,99 \pm 7,74$. $52 \%$ of the patients were followed-up in intensive care units, whereas $48 \%$ were followed-up in the clinics. The emergency internal medicine intensive care unit was the clinic with the highest number of geriatric patients, which was 45 (22,9\%). Eighty-five of 400 patients $(21,3 \%)$, who were all geriatric patients with determined nosocomial infection, died. The types of nosocomial infection were urinary system infection in $45,8 \%$, bloodstream infection in $32,9 \%$, pneumonia in $8,6 \%$ and surgical site infection in 7,8\%. A total of 289 microorganisms were isolated from 279 nosocomial infections. The infectious agents were Escherichia coli in 20,1\%, Klebsiella pneumoniae in 13,1\%, Acinetobacter baumannii in 10,7\%, Pseudomonas aeruginosa in 5,2\% and Candida spp in $4,8 \%$. The development of nosocomial infections was observed to be a mean of $20,88 \pm 16,83$ days as of the day of hospitalization. A total of 541 interventions were performed on 188 patients with nosocomial infection. These interventions were urinary catheter installation, peripheral and central venous catheter installation, mechanical ventilation and endotracheal intubation.

\section{Conclusion}

The mortality-survival rates in nosocomial infections of geriatric patients is $50 \%>50 \%$, and the risk factors were determined to be the interventional procedures, prolonged hospitalization and previous nosocomial infections.

\section{Disclosure of interest}

None declared.

\section{Author details}

${ }^{1}$ Infectious Diseases and Clinical Microbiology, Gulhane Military Hospital, Ankara, Turkey. ${ }^{2}$ Infection Control, Infection Control, Ankara, Turkey.

Published: 20 June 2013

\section{doi:10.1186/2047-2994-2-S1-P237}

Cite this article as: Gül et al:: P237: Nosocomial infections and infectious agents determined in geriatric patients. Antimicrobial Resistance and Infection Control 2013 2(Suppl 1):P237.

${ }^{1}$ Infectious Diseases and Clinical Microbiology, Gulhane Military Hospital,

Ankara, Turkey

Full list of author information is available at the end of the article

(c) 2013 Gül et al; licensee BioMed Central Ltd. This is an Open Access article distributed under the terms of the Creative Commons Attribution License (http://creativecommons.org/licenses/by/2.0), which permits unrestricted use, distribution, and reproduction in any medium, provided the original work is properly cited. 